\title{
Lung regeneration: Implantation of fetal rat lung fragments into adult rat lung parenchyma
}

\author{
Koichiro Kenzaki, MD, ${ }^{a}$ Shoji Sakiyama, MD, PhD, ${ }^{a}$ Kazuya Kondo, MD, PhD, ${ }^{\text {a }}$ Mitsuteru Yoshida, MD, ${ }^{a}$ \\ Yukikiyo Kawakami, MD, ${ }^{a}$ Masatsugu Takehisa, MD, ${ }^{a}$ Hiromitsu Takizawa, MD, ${ }^{a}$ Takanori Miyoshi, MD, PhD, \\ Yoshimi Bando, MD, PhD, ${ }^{\mathrm{b}}$ Akira Tangoku, MD, PhD, and Mingyao Liu, MD, PhD ${ }^{\mathrm{c}}$
}

From the Departments of Oncological and Regenerative Surgery ${ }^{\mathrm{a}}$ and Molecular and Environmental Pathology, ${ }^{\mathrm{b}}$ University of Tokushima Graduate School, Tokushima, Japan, and the Department of Surgery, University of Toronto, ${ }^{\mathrm{c}}$ Toronto, Ontario, Canada.

Received for publication Aug 22, 2005; revisions received Nov 2, 2005; accepted for publication Nov 14, 2005.

Address for reprints: Shoji Sakiyama, $\mathrm{MD}, \mathrm{PhD}$, Department of Oncological and Regenerative Surgery, University of Tokushima Graduate School, Kuramotocho 3, Tokushima, 770-8503, Japan (E-mail: sakiyama@clin.med.tokushima-u.ac.jp).

J Thorac Cardiovasc Surg 2006;131:1148-53 $0022-5223 / \$ 32.00$

Copyright $\odot 2006$ by The American Association for Thoracic Surgery

doi:10.1016/j.jtcvs.2005.11.041
Objective: The capability of regeneration of lung tissues in adults is limited after chronic destruction. Bone marrow-derived stem cells, retinoic acid, growth factors, and other approaches have been attempted to promote or facilitate this process. We hypothesized that fetal lung tissues, with great potential for growth and differentiation, could be used for lung regeneration.

Methods: Day 17 fetal lung tissue fragments at the pseudoglandular stage of lung development from Lewis rats were implanted into adult Lewis rat lungs. For group 1, fetal lung fragments were injected into the adult left lung parenchyma; for group 2, fetal fragments were injected with the left lung partially resected; for group 3, adult fragments were injected; and for groups 4 and 5, fetal fragments were implanted into the omentum and subcutaneous tissue, respectively.

Results: The grafts implanted into pulmonary parenchyma were differentiated with opening of the alveolar space after 4 weeks and were advanced further with morphologic features similar to those of neonatal lungs after 8 and 12 weeks. The implants were connected with pulmonary circulation determined by means of perfusion with India ink. These changes appeared to be further enhanced in animals with partial lung resection that might have facilitated the maturation of implanted fetal lung tissues through mechanical factors, soluble factors, or both. Fetal lung tissues did not mature when implanted into the omentum or subcutaneous tissue. Adult lung fragments did not expand after being reimplanted back into the same animal.

Conclusions: Fetal lung tissue might be an option for further investigation into lung regeneration.

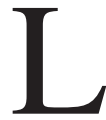

ung cells and tissues undergo continuous damage, repair, and regeneration throughout life. Generally, acute injury to lung cells and tissues is remedied by the body's repair mechanisms, but improper repair might lead to chronic diseases, such as chronic obstructive pulmonary disease, asthma, and pulmonary fibrosis. ${ }^{1}$ When the destruction of lung tissues persists, lung cells and tissues cannot be repaired and regenerated, and emphysema and other severe diseases that cause the dramatic destruction of lung tissues occur. ${ }^{2}$ Traditionally, it is believed that the capability of lung regeneration is limited, but this concept has been challenged by recent observations. For example, Massaro and coworkers ${ }^{3}$ showed that calorie restriction leads to the rapid loss of alveolar units, which can be corrected by means of ad libitum refeeding in mice. This endogenous programmed destruction and regeneration of alveolar units ${ }^{4}$ might have significant physiologic meaning. However, there is no evidence that this type of reversible regeneration occurs in human subjects, especially under severe diseased conditions. Retinoic acid ${ }^{5}$ and growth factors ${ }^{6}$ play important roles in fetal lung development. Specifically, retinoic acid 


\section{Abbreviations and Acronyms}

$\mathrm{Lm}=$ mean linear intercept

reverses anatomic and physiologic signs of pulmonary emphysema in an animal model. ${ }^{7}$ Also, keratinocyte and hapatocyte growth factors ${ }^{8,9}$ have been used to promote the repair of lung tissue after acute injury. ${ }^{10}$ However, whether these growth factors promote regeneration of the lung tissue remains to be determined.

Using a bleomycin-induced lung injury model, Kotton and colleagues ${ }^{11}$ showed that intravenously delivered bone marrow-derived stem cells can be integrated into alveolar epithelium and that these cells possess features of type I pneumocytes. On the basis of current techniques, however, the number of bone marrow-derived cells that can be integrated into the alveolar epithelium is limited. Instillation of lipopolysaccharide through the trachea induces the rapid mobilization of bone marrow-derived progenitor cells into the circulation in mice, which accumulate within inflammatory sites and differentiate to become endothelial and epithelial cells. ${ }^{12}$ These cells might participate in repair of the lung, but whether they can initiate tissue regeneration remains to be elucidated. Furthermore, Hashimoto and associates $^{13}$ found that bone marrow-derived progenitor cells can also become collagen-production fibroblasts and contribute to pulmonary fibrosis in a bleomycin-induced lung injury model. Therefore stem cell-based therapy needs to be developed with caution.

Fetal rat cardiomyocytes have been injected into adult rat myocardial scar tissues, resulting in improved heart function. ${ }^{14}$ Although many other cell types have also been used and found to exert similar beneficial effects on the heart, ${ }^{15}$ the potent capability of further proliferation and differentiation of fetal cells is a very attractive feature. However, it is hard to imagine that injecting a single type of fetal lung cell might restore the structure and function of alveolar units. For gas exchange, ventilation in the alveolar space has to match the perfusion of blood in the pulmonary capillary. The 3-dimensional complex architectural features of alveoli with multiple cellular compositions make lung generation extremely challenging.

Fetal lung tissues have great potential to further grow and differentiate. ${ }^{16}$ We hypothesized that fetal lung tissue grafts could be used as seeds to provide microcenters for lung tissue regeneration. In the present study we transplanted fetal rat lung fragments into the adult rat lung and then examined their integration with adult lung tissue through the airway and the pulmonary vasculature. Partial lung resection induces compensatory growth of lung tissue in young adults. ${ }^{17}$ We found that this approach enhanced the integra- tion and maturation of implanted fetal lung tissues in the adult rat lung.

\section{Materials and Methods}

The procedures in this study that were performed on animals were approved by the Animal Care Committee of the University of Tokushima. Specific pathogen-free male Lewis rats aged approximately 8 to 12 weeks and pregnant rats at 17 days' gestation were obtained from Charles River Japan and received humane care in compliance with the Institute of Laboratory Animal Resources, Commission on Life Sciences of the National Research Council's "Guide for the care and use of laboratory animals" (National Academy Press, Washington, DC, 1996).

Pregnant rats, after achievement of ether-induced anesthesia, were killed, their fetuses were removed, and the fetal lungs were dissected under a microscope, cut into very fine pieces, and stored in Dulbecco's modified Eagle's medium containing $10 \%$ fetal bovine serum and penicillin-streptomycin (Gibco-BRL). ${ }^{18}$

Adult rats were ventilated with a small animal respirator (SN480-7, Shinano) at 70 cycles/min, a tidal volume of $10 \mathrm{~mL} / \mathrm{kg}$, and a positive end-expiratory pressure of $2 \mathrm{~cm} \mathrm{H}_{2} \mathrm{O}$ under atropine sulfate at $0.1 \mathrm{mg} /$ body (administered subcutaneously) and $1.5 \%$ halothane $\left(\mathrm{N}_{2} \mathrm{O}: \mathrm{O}_{2}=1: 1\right)$. There were 5 treatment groups. For group 1, after left thoracotomy, fetal lung fragments were injected just under a pleura of the left lung apex, where $0.1 \mathrm{~mL}$ contained lung fragments from 2 fetuses, using a $0.25-\mathrm{mL}$ syringe and 20 -gauge needle. The area of the small cut was covered with a fibrin sheet. For group 2, after injecting fetal lung grafts, the left lung under the level of the pulmonary vein was ligated and resected. The postcaval lobe was also resected to avoid it shifting to the left thoracic cavity. For group 3, autologous lung fragments from the resected postcaval lobe were injected into the left lung apex. For group 4, fetal lung fragments were implanted into the omentum by wrapping in the omentum after laparotomy. Finally, for group 5, fetal lung fragments were subcutaneously embedded between the blade bones. Animals were killed 1, 2, 4, 8, and 12 weeks after implantation. At each time point, 5 animals were used per group.

\section{Histologic Study}

Lungs were perfused with saline through the pulmonary artery after cutting the left atrium and then removed en bloc with the heart and fixed with $10 \%$ phosphate-buffered formalin solution from the trachea at $15 \mathrm{~cm} \mathrm{H}_{2} \mathrm{O}$. Day 17 fetal rat lungs and postnatal day 1 and 7 lungs were also fixed in $10 \%$ formalin. The omentum and subcutaneous tissues containing the transplanted tissues were removed and fixed with $10 \%$ formalin. Specimens embedded in paraffin were cut at 4- $\mu \mathrm{m}$ thickness and stained with hematoxylin and eosin and Masson trichrome. India ink $(5 \times$ dilution) was injected through the pulmonary artery after perfusing the lung with saline during clamping of the inferior vena cava to determine the blood supply from the adult pulmonary circulation to fetal lung tissues. The fixed lung tissues were serially cut and stained with or without hematoxylin and eosin. Light microscopic images from histologic specimens were then captured by using FUJIX Photograb-300Z (Fuji Photo Film Co, Ltd).

To quantify lung expansion after partial lung resection, the mean linear intercept (Lm) method was used. Briefly, 5 fields 
under light microscopy at $200 \times$ magnification were randomly selected from each lung, and the Lm was calculated on the basis of the total number of alveolar intercepts encountered along the line of the length of a right-angled cross hair $(500 \mu \mathrm{m}) .{ }^{19}$ A higher Lm value reflects the expansion of alveolar size.

\section{Statistical Analysis}

The results are expressed as the mean \pm standard deviation. Statistical analysis was performed by using the paired Student $t$ test with SPSS software (Version 11.0.1, SPSS).

\section{Results}

\section{Maturation and Integration of Fetal Lung Tissues in the Adult Rat Lung}

The term of rat pregnancy is 22 days and can be divided into embryonic (before day 15) and subsequent fetal stages. From day 15 to day 17, the fetal rat lung is in the pseudoglandular stage, which is followed by the canalicular (days 18 and 19) and saccular (days 20-22) stages. ${ }^{16,20}$ The final alveolar stage occurs postnatally in rats. ${ }^{21}$ For the lung histology of a day 17 fetus, day 1 and 7 newborn rats are shown as landmarks for lung maturation (Figure 1). The alveolar space in the day 17 fetal lung was not yet fully open. The fluid compartment can only be seen in the large airway. Also, the epithelial cells appeared to be cuboidal in shape (Figure 1, A). One day after birth, air-filled structures were seen with septal crests, which were different from true septa and alveolar. The septal thickness reflected greater interstitial cellularity and matrix (Figure 1, B). Seven days later, the alveoli were fully developed. The alveolar surface was covered mainly by thin type I pneumocytes (Figure 1,C).

When day 17 fetal rat lung tissues, which have pseudoglandular structures, were implanted into the adult rat lung, they underwent further development. After 8 weeks, the alveolar spaces were fully open, filled with air, and connected to the surrounding adult lung tissues (Figure 1,D). Interestingly, the border zone between the implanted fetal lung tissue and the adult lung tissue still existed. Compared with the alveoli in the surrounding adult lungs, the sizes of alveoli in fetal lung tissues were greater. The morphologic features of the alveolar septa looked more like those of the day 7 postnatal lung (Figure 1,C). Nevertheless, this result suggests that fetal lung tissue was able to develop further in the adult lung tissue.

This effect is tissue specific. When fetal lung tissues were embedded into the rat omentum, they did not further differentiate after 8 weeks. The implanted fetal lung tissues were surrounded by soft connective tissues (figure not shown). The potential alveolar spaces seen in the fetal lungs disappeared. Instead, fresh hemorrhaging was seen in the lung tissue (not shown). When the fetal lung tissues were subcutaneously embedded, the lung tissues also did not further differentiate, and more severe hemorrhaging appeared inside the potential alveolar spaces (not shown).

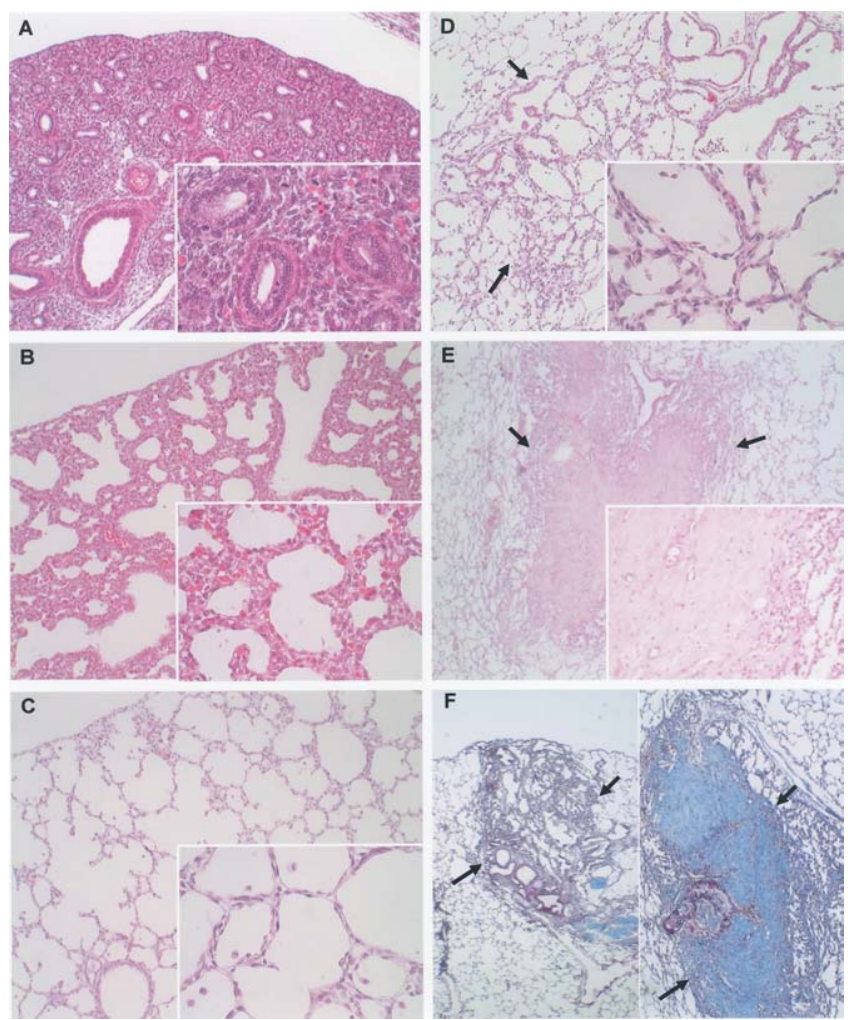

Figure 1. Adaptation and maturation of fetal rat lung tissue in the adult rat lung. The morphology of fetal and neonatal lung tissues is presented as a landmark for lung maturation. A, Day 17 fetal rat lung (pseudoglandular stage, term is 22 days). B, Day 1 after birth (alveolar stage). C, Day 7 after birth. D, Day 17 fetal rat lung tissue fragments were implanted into the apical site of the left lung in adult rats. Eight weeks later, the morphologies of fetal lung tissues and surrounding tissues were examined. Hematoxylin and eosin-stained specimens are shown at $100 \times$ and $400 \times$ magnification as insets. The morphology of fetal lung tissue looked like that of day 7 postnatal lungs. E, After partial lung resection, dissected adult lung tissues were minced and injected in a fashion similar to that of the fetal lung tissue fragments into the apical site of the left lung. Specimens were collected after 4 weeks. Hematoxylin and eosin-stained specimens are shown at $40 \times$ and $200 \times$ magnification as insets. F, Specimens of fetal grafts (left) and autologous grafts (right) after 4 weeks were used for Masson trichrome staining at $40 \times$ magnification. Each photo is representative of 5 animals that were treated in the same way. Arrows show the border zones between injected and native tissues.

Partial Lung Resection Enhanced Opening of Alveolar Units in the Fetal Lung

Physical forces play an important role in fetal and neonatal lung growth and maturation ${ }^{21}$ and are also important factors in the regulation of adult lung cellular functions. ${ }^{22}$ Partial lung resection, for example, might induce compensatory 


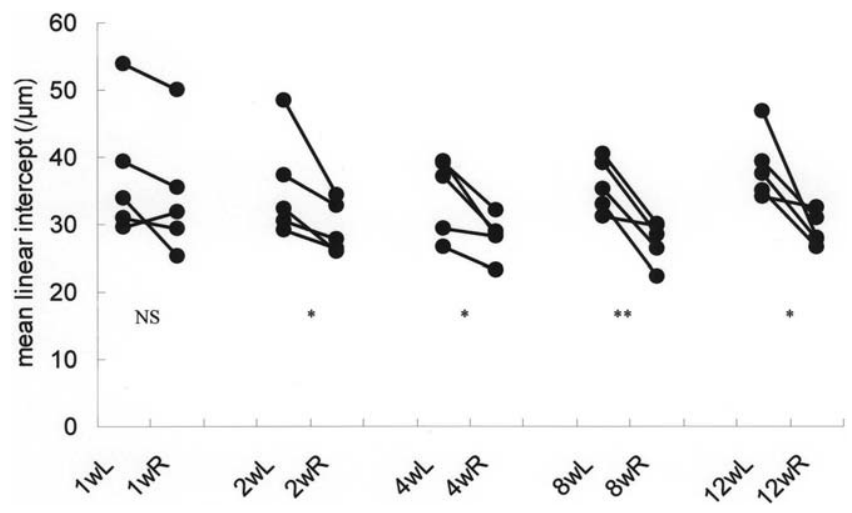

Figure 2. Partial lung resection induced left lung expansion. Partial lung resection was performed on the left lung. Right and left lung tissues were examined after 1, 2, 4, 8, and 12 weeks. The mean linear intercept $(\mathrm{Lm})$ of alveoli was calculated by using the Thurlbeck method at $200 \times$ magnification. Each dot is the $\mathrm{Lm}$ of 5 random fields from the same specimen. Five animals were examined at each time point. The higher $\mathrm{Lm}$ value reflects the expansion of alveolar size in the left lung. ${ }^{*} P<.05$ and ${ }^{*} P<.01$ between left and right $\mathrm{Lm}$. $w$, Weeks after lung resection; $L$, left lung; $R$, right lung; NS, not significant.

lung growth in young adults by creating more space and mechanical stretching of lung tissues. ${ }^{23}$ We rationalized that by injecting minced lung tissues into the adult lung, these tissue fragments could be compressed by surrounding tissues. Furthermore, tissue implantation could be used to treat diseased lung tissue, such as that in patients with emphysema, which is less dense than normal lung tissue. To test whether a reduced lung volume with less tissue density could enhance opening of alveolar units derived from fetal lung tissues in the adult lung, we performed lung resection to partially remove the left lung and postcaval lobe of the recipient. Morphometric analyses of the left and right lungs were performed to determine whether partial lung resection indeed reduced the lung tissue density. Compared with the right lung of the same animal, the Lm of alveoli in the left lung, where the partial lung resection was performed, was higher since the second week after the lung resection (Figure 2). Thus partial lung resection led the residual left lung to the status of overinflation, which indirectly suggests that fetal lung tissues embedded within the left lung were subjected to more mechanical stretch.

We then compared the morphology of fetal rat lung tissues in the adult lung with or without partial lung resection. One week after implantation without lung resection, the grafted tissue had similar morphology (Figure 3, A, left) as that of the day 17 fetal lung (Figure 1, A), whereas in the lung resection group large air spaces were seen in the grafts, even though the majority of alveolar units were still not open (Figure 3, A, right). Starting from the second week, the
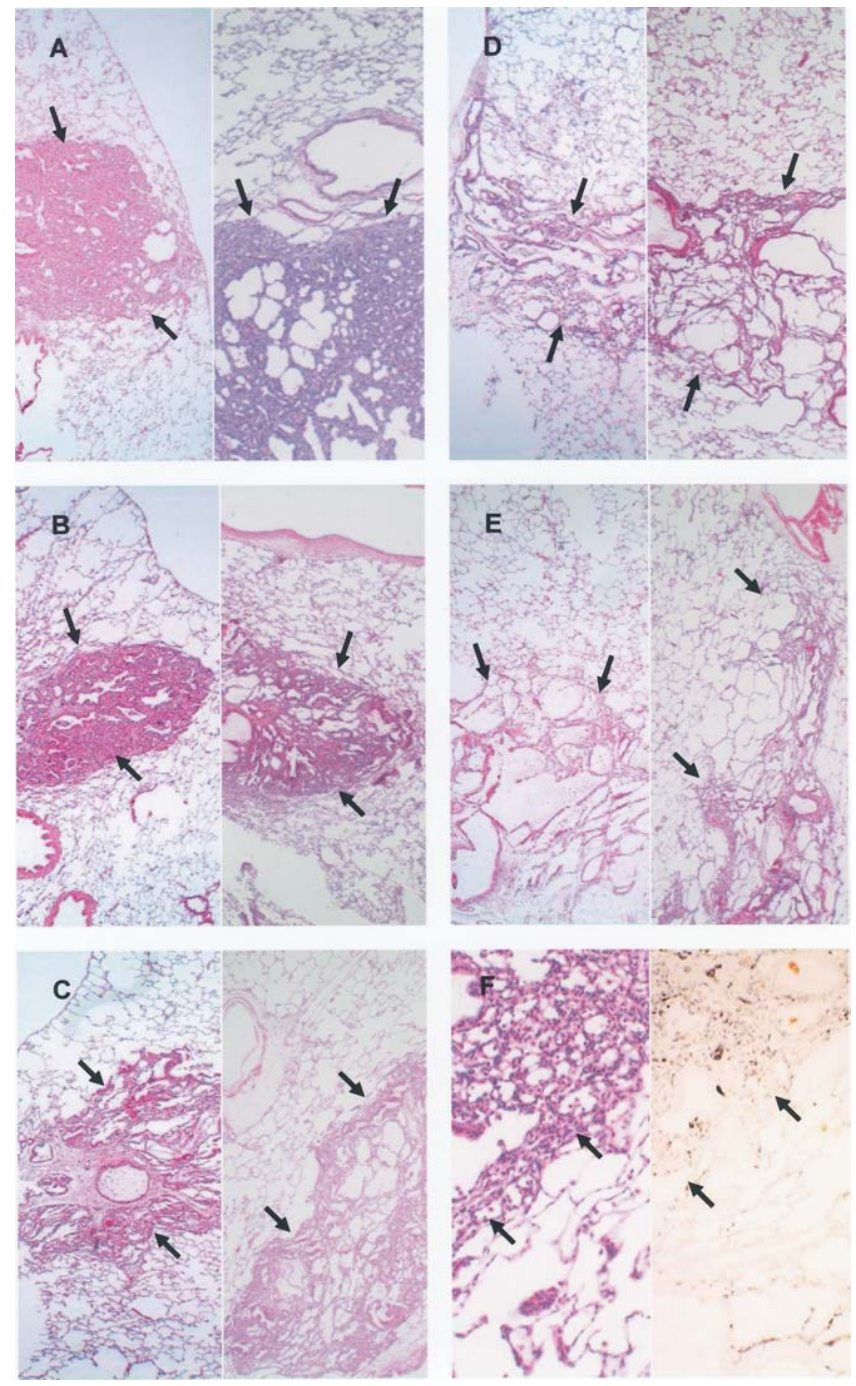

Figure 3. Partial lung resection enhanced fetal lung expansion and maturation in adult lungs. Animals were randomly divided into $\mathbf{2}$ groups, with or without partial lung resection, and fetal lung tissues and the surrounding area were examined after $1(A)$, 2 (B), 4 (C), 8 (D), and 12 (E) weeks. Hematoxylin and eosinstained specimens are shown at $40 \times$ magnification. For each panel, a specimen from the partial lung resection group is on the right, and a specimen without lung resection is on the left. Each photo is representative of 5 animals that were treated in the same way. F, Connection of implanted fetal lung tissues with the pulmonary circulation. Four weeks after implantation, rat lungs were flushed through the pulmonary artery and filled with India ink. Left, A hematoxylin and eosin-stained specimen at $200 \times$ magnification showing the border zone between the fetal lung tissues and surrounding area (arrow). Right, A nonstained serial section at $200 \times$ magnification showing the distribution of India ink in fetal and adult lung tissues. Arrows show the border zones between injected and native tissues. 
air spaces were gradually increased in both groups, but the grafts within lung resection groups had more units filled with air, and the alveolar septa thinned out faster than in the lungs in the groups without lung resection (Figure 3,B-E). After 8 to 12 weeks, most of the implanted fetal lung tissues were filled with air, and the histologic features of the tissues were more like those of postnatal lungs than those of fetal lungs (see Figure 1 for comparison). With partial lung resection, the aeration of fetal lung tissues in the adult pulmonary parenchyma appeared to be accelerated.

\section{Connection of Grafted Fetal Lung Tissues With Pulmonary Circulation}

The implanted lung tissues must be connected with the pulmonary vasculature to achieve long-term survival and gas exchange. To determine the connection of blood vessels with the pulmonary circulation, we perfused the pulmonary artery with India ink and examined the distribution of black stains in the lung tissues. Lungs after 4 weeks of implantation were chosen because the border zone between the implanted fetal lung tissue and surrounding adult lung tissue is distinct (Figure 3, F, left). The alveolar septa were clearly highlighted by the India ink in the adult lung. Similarly, the ink also outlined the potential alveolar units in the fetal tissues (Figure 3, F, right). This indicates that the re-establishment of blood perfusion in the implanted fetal lung tissues occurred at least before the end of the 4 weeks.

\section{Adult Lung Grafts Did Not Show Adaptation After Autoimplantation}

To determine whether the observed accommodation of grafts is specific for fetal lung tissue after lung resection, we also cut the removed adult lung tissues into very fine pieces and implanted them back into the apical site of the left lung for comparison. After 1, 2, 4, 8, and 12 weeks, the implanted autologous grafts did not expand (Figure 1,E). We then used Masson trichrome staining to compare the fetal and adult grafts at all weeks after the implantation. Significant fibrotic changes were seen in the adult grafts (Figure 1, F), suggesting that adult autologous lung tissues survived poorly under the same experimental conditions.

\section{Discussion}

In the present study we found that fetal lung tissues could survive and further grow and differentiate inside adult lungs. Furthermore, these grafts were filled with air and were connected to the pulmonary circulation. These results suggest that fetal lung tissue might be a potential candidate for lung regeneration to treat destructive diseases of the lung. Our results indicate that the adoption and further expansion of lung implantation in the adult lung is dependent on gestation. Autologous lung grafts from young adult rats did not survive after implantation under this experimental condition. The growth and differentiation capacity of fetal lung cells and tissues appears to be essential and leads to the further development of alveolar units. Fetal lung tissues express many growth factors and receptors that are dependent on gestation. ${ }^{16}$ It will be interesting and important to compare the capability of fetal lungs of various gestational stages, such as the canalicular and saccular stages, and those from neonatal lungs to determine what is the best stage for tissue-based therapy.

To avoid immune responses between the grafts and the host, we used an inbred strain, Lewis rats, for fetal and adult animals. Therefore transplantation between the donors and receipts was isogeneic. For therapeutic purposes, allogeneic combination needs to be tested. As a proof-of-principle study, we injected fetal lung tissue fragments through an open chest approach. For therapeutic purposes, instillation of a suspension containing lung tissue fragments through the airway should be considered.

One of the experimental strategies used in the present study was lung volume reduction through partial removal of the left lung and the postcaval lobe of the adult rat lung, which enhanced the aeration of the implanted fetal rat lung tissues. We also found that the partial lung resection led to expansion of the alveolar spaces in the left lung, indirectly measured by the Lm of the alveoli. It has been suggested that mechanical forces contribute to the compensatory growth of the lungs in young adults. ${ }^{17,23}$ Mechanical stretching also stimulates fetal lung cell proliferation ${ }^{18}$ and differentiation. ${ }^{24,25} \mathrm{Re}$ cently, it was shown that mechanical forces can also stimulate type II pneumocyte maturation. ${ }^{26,27}$ Partial lung resection might increase the release of growth factors and other soluble factors, which can stimulate lung cell growth and differentiation. ${ }^{9}$ We postulate that partial resection of adult lungs facilitates proliferation and maturation of transplanted fetal tissues. In this situation we postulated that the mechanical force induced by partial resection caused 2 actions affecting transplanted fetal tissues: growth factor and a pure mechanical phenomenon.

After 8 to 12 weeks, the fetal lung tissues exhibited phenotypes similar to those of neonatal lungs. However, we did notice that the sizes of the alveolar units were larger than those in the surrounding adult lungs. This morphologic feature suggests that although the lung epithelial cells changed from pseudoglandular shape to thinner and type I-like pneumocytes, it is known whether the number of the alveolar units increased. We intended to use fetal lung tissues as seeds to promote or generate more alveolar units in the recipient lung. There is a possibility that the fetal tissues in adult lungs are replaced by the cells derived from the hosts in the long term. In this situation the fetal tissue implants used as a scaffold might be useful for repairing injured lung tissues.

On the basis of the morphology observed in the present study, only implanting minced lung tissues might not allow 
this goal to be achieved. Retinoic acid stimulates lung regeneration in an elastase-induced emphysema model of the rat lung ${ }^{7}$ and promotes lung tissue repair in other animal models. Other factors, such as hepatocyte growth factor ${ }^{9}$ and keratinocyte growth factor, ${ }^{28}$ also promote lung cell proliferation and maturation. Admission of these agents into the adult lung might enhance the cell proliferation of implanted fetal lung tissue.

We are left with the question of which cells are responsible for the tissue growth or repair. Identification of a particular cell type or group of cells within either the fetal lung fragments or the adult lung (endogenous stem cells, Clara cells, type II pneumocytes, neuroendocirne cells, and endothelial cells) might be used for clinical therapies. Host bone marrow-derived mesenchymal stem cells ${ }^{29}$ and multipotent adult progenitor cells ${ }^{30}$ might also contribute to tissue growth or repair in our experimental model. In addition to these technical issues, using fetal lung tissue to treat adult human diseases might be of ethical concern. Whether this could be a clinical option depends on many other cofounding factors. Nevertheless, results from the present study indicate that the implantation of structurally organized tissues should be considered for regenerative studies of the lung.

\section{References}

1. Davies HR, Richeldi L. Idiopathic pulmonary fibrosis: current and future treatment options. Am J Respir Med. 2002;1:211-24.

2. Aoshiba K, Yokohori N, Nagai A. Alveolar wall apoptosis causes lung destruction and emphysematous changes. Am J Respir Cell Mol Biol. 2003;28:555-62.

3. Massaro D, Massaro GD, Baras A, Hoffman EP, Clerch LB. Calorierelated rapid onset of alveolar loss, regeneration, and changes in mouse lung gene expression. Am J Physiol Lung Cell Mol Physiol. 2004;286: L896-906.

4. Massaro GD, Radaeva S, Clerch LB, Massaro D. Lung alveoli: endogenous programmed destruction and regeneration. Am J Physiol Lung Cell Mol Physiol. 2002;283:L305.

5. Kaza AK, Kron IL, Kern JA, Long SM, Fiser SM, Nguyen RP, et al. Retinoic acid enhances lung growth after pneumonectomy. Ann Thorac Surg. 2001;71:1645-50.

6. Ohmichi H, Koshimizu U, Matsumoto K, Nakamura T. Hepatocyte growth factor (HGF) acts as a mesenchyme-derived morphogenic factor during fetal lung development. Development. 1998;125:1315-24.

7. Massaro GD, Massaro D. Retinoic acid treatment abrogates elastaseinduced pulmonary emphysema in rats. Nat Med. 1997;3:675-7.

8. Yano T, Mason RJ, Pan T, Deterding RR, Nielsen LD, Shannon JM. KGF regulates pulmonary epithelial proliferation and surfactant protein gene expression in adult rat lung. Am J Physiol Lung Cell Mol Physiol. 2000;279:L1146-58.

9. Sakamaki Y, Matsumoto K, Mizuno S, Miyoshi S, Matsuda H, Nakamura T. Hepatocyte growth factor stimulates proliferation of respiratory epithelial cells during postpneumonectomy compensatory lung growth in mice. Am J Respir Cell Mol Biol. 2002;26:525-33.
10. Ware LB, Matthay MA. Keratinocyte and hepatocyte growth factors in the lung: role in lung development, inflammation, and repair. Am J Physiol Lung Cell Mol Physiol. 2002;282:L924-40.

11. Kotton DN, Ma BY, Cardoso WV, Sanderson EA, Summer RS, Williams MC, et al. Bone marrow-derived cells as progenitors of lung alveolar epithelium. Development. 2001;128:5181-8.

12. Yamada M, Kubo H, Kobayashi S, Ishizawa K, Numasaki M, Ueda S, et al. Bone marrow-derived progenitor cells are important for lung repair after lipopolysaccharide-induced lung injury. J Immunol. 2004; 172:1266-72.

13. Hashimoto N, Jin H, Liu T, Chensue SW, Phan SH. Bone marrowderived progenitor cells in pulmonary fibrosis. J Clin Invest. 2004; 113:243-52.

14. Li RK, Mickle DA, Weisel RD, Mohabeer MK, Zhang J, Rao V, et al. Natural history of fetal rat cardiomyocytes transplanted into adult rat myocardial scar tissue. Circulation. 1997;96(suppl):II179-87.

15. Itescu S, Schuster MD, Kocher AA. New directions in strategies using cell therapy for heart disease. $J$ Mol Med. 2003;81:288-96.

16. Copland I, Post M. Lung development and fetal lung growth. Paediatr Respir Rev. 2004;5(suppl):S259-64.

17. Brown LM, Rannels SR, Rannels DE. Implications of postpneumonectomy compensatory lung growth in pulmonary physiology and disease. Respir Res. 2001;2:340-7.

18. Liu M, Xu J, Tanswell AK, Post M. Stretch-induced growth-promoting activities stimulate fetal rat lung epithelial cell proliferation. Exp Lung Res. 1993;19:505-17.

19. Thurlbeck WM. The internal surface area of nonemphysematous lungs. Am Rev Respir Dis. 1967;95:765-73.

20. Marszalek A, Biczysko W, Wasowicz M. Development of the fetal and newborn lung —-morphometric studies (rat model). Pol J Pathol. 1999; 50:277-88.

21. Liu M, Post M. Invited review: mechanochemical signal transduction in the fetal lung. $J$ Appl Physiol. 2000;89:2078-84.

22. Liu M, Tanswell AK, Post M. Mechanical force-induced signal transduction in lung cells. Am J Physiol Lung Cell Mol Physiol. 1999;277: L667-83.

23. Tronc F, Gregoire J, Leblanc P, Deslauriers J. Physiologic consequences of pneumonectomy. Consequences on the pulmonary function. Chest Surg Clin N Am. 1999;9:459-73.

24. Xu J, Liu M, Post M. Differential regulation of extracellular matrix molecules by mechanical strain of fetal lung cells. Am J Physiol Lung Cell Mol Physiol. 1999;276:L728-35.

25. Mourgeon E, Xu J, Tanswell AK, Liu M, Post M. Mechanical straininduced posttranscriptional regulation of fibronectin production in fetal lung cells. Am J Physiol Lung Cell Mol Physiol. 1999;277: L142-9.

26. Edwards YS. Stretch stimulation: its effects on alveolar type II cell function in the lung. Comp Biochem Physiol A Mol Integr Physiol. 2001;129:245-60

27. Sanchez-Esteban J, Wang Y, Gruppuso PA, Rubin LP. Mechanical stretch induces fetal type II cell differentiation via an epidermal growth factor receptor-extracellular-regulated protein kinase signaling pathway. Am J Respir Cell Mol Biol. 2004;30:76-83.

28. Kaza AK, Kron IL, Leuwerke SM, Tribble CG, Laubach VE. Keratinocyte growth factor enhances post-pneumonectomy lung growth by alveolar proliferation. Circulation. 2002;106(suppl):I120-4.

29. Krause DS, Theise ND, Collector MI, Henegariu O, Hwang S, Gardner $\mathrm{R}$, et al. Multi-organ, multi-lineage engraftment by a single bone marrow-derived stem cell. Cell. 2001;105:369-77.

30. Jiang Y, Jahagirdar BN, Reinhardt RL, Schwartz RE, Keene CD, Ortiz-Gonzalez XR, et al. Pluripotency of mesenchymal stem cells derived from adult marrow. Nature. 2002;418:41-9. 